Jurnal Common | Volume 4 Nomor 2 | Desember 2020

Website: https://ojs.unikom.ac.id/index.php/common

DOI Jurnal: https://doi.org/10.34010/common

DOI Artikel: https://doi.org/10.34010/common.v4i2.3284

\title{
POLA KOMUNIKASI SINGLE PARENT TERHADAP PERKEMBANGAN KARAKTER ANAK
}

\author{
Nisrina Syifa Aisy ${ }^{1}$, Veny Purba ${ }^{2}$ \\ Ilmu Komunikasi Fakultas Ilmu Komunikasi dan Desain Universitas Adirajasa Reswara Sanjaya, Jl. Sekolah \\ Internasional No. 1-2 Antapani, Kota Bandung, 40282, Indonesia \\ E-mail: \\ nisrinasyifaaa@gmail.com ${ }^{1}$,boyveny@gmail.com²
}

\begin{abstract}
The pattern of communication between single parent and child is very influential on the attitudes and behavior of children in everyday life, but the case of single parent parents has two factors, namely divorced parents and parents who died. the influence of interpersonal communication in the communication patterns of single parent parents when carrying out their role as parents who must provide moral and moral support to the formation of children's character. This study aims to determine the effect of communication patterns of single parent parents on children's character building. This research uses qualitative methods with a phenomenological study. The research subjects were single fathers and single mothers. Data collection using observation and interview methods. The results of the research on the subject indicate that the communication pattern between single parent and child is very important in shaping the character of the child. Subjects have several obstacles in carrying out their roles, and some of them have obstacles in playing the role of father / mother for children.
\end{abstract}

Keywords: Communication patterns, single parent parents, children's character formation, roles.

\begin{abstract}
Abstrak
Pola komunikasi antara orang tua single parent terhadap anak sangat berpengaruh terhadap perkembangan karakter anak dikehidupan sehari-hari, namun menjadi orang tua single parent disebabkan karena dua faktor ditinggal kan karena meninggal dunia dan ditinggalkan karena bercerai. pengaruh komunikasi interpersonal didalam pola komunikasi orang tua single parent saat menjalankan perannya sebagai orang tua yang harus memberikan dukungan moral maupun moril terhadap pembentukkan karakter anak. Penelitian ini bertujuan untuk mengetahui pengaruh pola komunikasi orang tua single parent terhadap pembentukkan karakter anak. Dalam penelitian ini peneliti menggunakan metode kualitatif dengan studi fenomenologi. Subjek penelitian single father dan single mother. Pengumpulan data menggunakan metode observasi dan wawancara. Hasil penelitian pada subjek menunjukkan bahwa pola komunikasi antara orang tua single parent dan anak sangatlah penting dalam membentuk karakter anak. Subjek mempunyai beberapa hambatan dalam menjalankan peran mereka, dan beberapa diantara mereka mempunyai hambatan dalam memerankan peran ayah/ibu bagi anak.
\end{abstract}

Kata Kunci: Pola komunikasi, orang tua single parent, pembentukan karakter anak, peran. 


\section{Pendahuluan}

\subsection{Latar Belakang}

Komunikasi adalah suatu gagasan dalam menyampaikan pesan kepada komunikan. Komunikasi keluarga yaitu di mana didalam komunikasi tersebut terdapat unsur mendidik anak, pembentukan sikap anak dan juga pembentukkan perilaku anak, karena berpengaruh dalam pembentukkan karakter anak. Perubahan yang terjadi dalam pola keluarga yang berpengaruh pada komponen keluarga ayah,ibu dan anak maupun keluarga yang berkaitan dengan keluarga inti. Ikatan dengan keluarga yang renggang berpengaruh terhadap anak, karena anak akan memikul beban perubahan dari keluarga itu sendiri, anak akan lebih sering menghabiskan waktu diluar rumah, karena dia tidak menemukan kenyamanan didalam rumahnya. Fungsi keluarga saat ini adalah menanamkan nilai-nilai norma masyarakat, namun saat ini perubahan keluarga sering terjadi, sehingga berakibat hilangnya penanaman nilai yang dilakukan oleh keluarga terutama orang tua. Keutuhan keluarga dapat mebentuk karakter anak dengan baik, keluarga yang utuh juga memberikan rasa percaya diri pada anak. fenomena yang terjadi di lingkungan masyarakat sehari-hari tentang keutuhan keluarga salah satunya menjadi single parent (orang tua tunggal). Menjadi orang tua single parent tentu tidak mudah di mana mereka harus memerankan dua peran sekaligus untuk mendidik dan membentuk karakter anaknya. menjadi orang tua single parent bisa terjadi karena perceraian dan ditinggal meninggal dunia oleh pasangannya. Berikut adalaha data perceraian yang berada di kota bandung tahun 2019:
Tabel 1 Data Perceraian di Kota Bandung 2019

\begin{tabular}{|c|c|c|c|}
\hline \multicolumn{4}{|c|}{$\begin{array}{l}\text { DATA PERCERAIAN TAHUN } 2019 \text { KOTA } \\
\text { BANDUNG }\end{array}$} \\
\hline \multirow[b]{2}{*}{ Bulan } & \multicolumn{2}{|c|}{ Jenis Perceraian } & \multirow{2}{*}{$\begin{array}{l}\text { Jumlah } \\
\text { Perceraian }\end{array}$} \\
\hline & $\begin{array}{l}\text { Cerai } \\
\text { Talak }\end{array}$ & $\begin{array}{l}\text { Cerai } \\
\text { Gugat }\end{array}$ & \\
\hline Januari & 163 & 509 & 672 \\
\hline $\begin{array}{c}\text { Februar } \\
\text { i }\end{array}$ & 136 & 353 & 489 \\
\hline Maret & 145 & 379 & 524 \\
\hline April & 94 & 347 & 441 \\
\hline Mei & 78 & 266 & 344 \\
\hline Juni & 81 & 382 & 463 \\
\hline Juli & 149 & 465 & 614 \\
\hline Agustus & 95 & 373 & 468 \\
\hline $\begin{array}{c}\text { Septem } \\
\text { ber }\end{array}$ & 120 & 383 & 503 \\
\hline Oktober & 126 & 433 & 559 \\
\hline $\begin{array}{c}\text { Novemb } \\
\text { er }\end{array}$ & 130 & 378 & 508 \\
\hline $\begin{array}{c}\text { Desemb } \\
\text { er }\end{array}$ & 96 & 403 & 499 \\
\hline Total & 1413 & 4671 & 6084 \\
\hline
\end{tabular}

Pada tabel di atas dapat dilihat bahwa perceraian gugat lebih banyak dibandingkan perceraian talak, di mana perceraian gugat adalah perceraian yang diajukan oleh pihak istri. Data tersebut diperoleh dari situs web kementrian agama.

Anak yang ditinggal oleh orang tuanya akan mengalami masalah psikologi dan psikisnya, mereka kehilangan salah satu peran dari orang tua mereka. Perceraian menjadi salah satu penyebab terjadinya single parent, tidak sedikit kemungkinnan jika menjadi single parent ditinggal meninggal oleh pasangannya. Dengan mengetahui pola komunikasi orang tua single parent yang baik dapat membentuk karakter anak yang baik pula.

\subsection{Rumusan Masalah}

Seperti yang diketahui di latar belakang masalah di atas adalah agar dapat ditemukannya bagaimana pola komunikasi orang tua single parent dalam pembetukkan karakter anak 
Website: https://ojs.unikom.ac.id/index.php/common

DOI Jurnal: https://doi.org/10.34010/common

DOI Artikel: https://doi.org/10.34010/common.v4i2.3284

dengan melakukan dua peran sekaligus dalam mendidik anak?

\subsection{Maksud dan Tujuan}

Maksud dari penelitian ini adalah ingin meningkatkan pola komunikasi orang tua single parent terhadap anaknya. tujuan dari penelitian ini ingin orang tua lebih memperhatikan cara mereka berkomunikasi kepada anaknya. jika irang tua kurang berkomunikasi dengan anak dapat mempengaruhi pembentukkan karakter dan sikap anak didalam kehidupan sehariharinya, lalu mencari apa saja solusi para orang tua single parent dalam menyelesaikan hambatan selama menjadi orang tua single parent. penelitian ini bertujuan agar peneliti mengetahui bagaimana cara orang tua single parent berkomunikasi dan memerankan peran ayah/ibu kepada anaknya.

\subsection{Kegunaan Penelitian}

Kegunaan penelitian ini untuk:

1. Memahami bagaimana cara orang tua single parent berkomunikasi dengan anaknya.

2. Memahami apa saja solusi dan hambatan komunikasi antara orang tua single parent terhadap anaknya

3. Mengetahui bagaimana orang tua single parent memerankan peran ayah dan ibu terhadap anaknya.

\section{Kajian Pustaka dan Kerangka Pemikiran}

\subsection{Komunikasi}

Komunikasi mempunyai istilah dari komunkasi itu sendiri yang mempunyai arti pemberitahuan atau pertukaran. Komunikasi itu sendiri mempunyai tujuan dalam bertukar pesan antara komunikator dan komunikan. (Wiryanto, 2004)

\subsection{Keluarga}

Keluarga adalah suatu ikatan perkawinan yang terdiri dari ayah,ibu, dan anak. Keluarga juga mempunyai kewajiban untuk memenuhi segala kebutuhan pangan,sandang, dan papan. Peran ayah dikeluarga sangat penting, karena ayah adalah kepala rumah tangga yang bertanggung jawab menafkahi istri dan anaknya. Peran ibu didalam keluarga sebagai pelengkap keseimbangan dikeluarga, ibu mengurus kebutuhan ayah dan anaknya.

\subsubsection{Fungsi Keluarga}

Keluarga merupakan organisasi sosial dengan lingkaran kecil, namun keluarga memiliki fungsi yang lebih lengkap. Untuk membentuk keluarga harus ada suami dan istri. Keluarga memiliki fungsi yang lengkap karena keluarga memerankan fungsi yang paling banyak dan sangat penting untuk anak. (Supriyono et al., 2015)

\subsection{Orang tua single parent}

Keluarga yang disebutkan utuh adalah keluarga yang masih lengkap antara anggota keluarga yang lain. Keluarga yang utuh itu mencakup kedua orang tua dan anak didalamnya. Namun berbeda dengan orang tua tunggal/ single parent, menjadi orang tua single parent bisa terjadi karena adanya perceraian dan ditinggalkan karena meninggal dunia. Kasus perceraian mendominasi terjadinya single parent. dengan begitu menjadi sosok single parent tentu tidak mudah, salah satu dari mereka yang ditinggalkan harus menggantikan peran orang tua yang hilang bagi anaknya.

\subsubsection{Pola Komunikasi Orang Tua Single Parent}

Pola komunikasi orang tua single parent adalah suatu gambaran dari proses komunikasi yang terorganisir melalui kata-kata atau sikap. Pola komunikasi orang tua single parent harus memiliki cara yang tepat untuk membentuk 
Website: https://ojs.unikom.ac.id/index.php/common

DOI Jurnal: https://doi.org/10.34010/common

DOI Artikel: https://doi.org/10.34010/common.v4i2.3284

karakter anak. komunikasi menurut sudjana (2000) ada 3 pola komunikasi:

1. Pola komunikasi dengan satu arah

2. Pola komunikasi yang dilakukan secara dua arah

3. Pola komunikasi yang dilakukan ke banyak arah (Sudjana, 2002).

\subsection{Teori Konstruktivisme}

Teori konstruktivisme adalah teori yang menjelaskan tentang individu yang berpengaruh besar terhadap perkembangan ilmu komunikasi. George Kelly menyatakan, setiap orang bisa memahami pengalamannya dengan menyatukan perbedaan yang pernah dia lalui. Teori ini mempunyai hasil interaksi sosial dan budaya dengan secara kognitif, tetapi teori konstruktivisme akan lebih mengutamakan pengamatan dengan lebih jelas, konstruksi personal dan strategi juga digunakan untuk berkomunikasi. Sistem konstruksi personal berkembang sejak anak-anak hingga dewasa, namun tingkat perkembangan berbeda-beda di setiap orangnya. kompleksitas kognitif orang dewasa berbeda-beda, bahkan disetiap konstruksi personal yang ada dalam diri satu individu, mereka mempunyai cara yang berbeda. (Morissan, 2018).

\subsection{Teori Peran}

Teori peran lebih menggambarkan tentang harapan peran yang merupakan pemahaman untuk menuntun kita agar dapar berprilaku sesuai dengan peran kita dalam kehidupan sehari-hari (Sarwono, 2010). Teori peran dapat dukaitkan dengan hubungan antara 2 orang dan bisad ikaitkan juga dengan banyak orang. dalam teorinya Biddle dan Thomas mempunyai peristilahan yaitu teori peristilahan dalam teori peran mempunyai empat golongan yaitu:

1. Manusia yang bisa berinteraksi

2. Munculnya prilaku dalam berkomunikasi.

3. Peranan orang dalam berprilaku dan berinteraksi.
4. Kaitan antara orang dalam prilaku mereka.

Teori peran berhubungan dengan hubungan komunikasi interpersonal di mana individu yang terlibat dalam komunikasi interpersonal diharuskan untuk memainkan perannya dalam kehidupan seharari-hari dan dikehidupan masyarakat. Dalam kehidupan sehari-hari peran memiliki posisi masing-masing sebagai berikut:

1. Role Expectation (Harapan Peran)

2. Peran ganda

\subsection{Kerangka Pemikiran}

Dalam penelitian ini dikembangkanlah salah satu konsep atau kerangka penelitian, dengan tujuan agar mempermudah penelitian penulis dalam melakukan penelitiannya. Dengan adanya kerangka penelitian, maka tujuan yang akan dilakukan oleh peneliti semakin jelas karena sudah terkonsep.

Pengaruh yang disebabkan dari orang tua yang kurang beromunikasi dengan anaknya akan membawa pengaruh buruk, namun bila orang tua single parent sering berkomnikasi dengan anak maka akan ada dampak baik bagi pembentukkan karakter anak. karena pada dasarnya peran orang tua sangatlah penting dalam mendampingi anak untuk menciptakan kepribadian dan karakter yang baik. Pola komunikasi orang tua single parent sangat berpengaruh terhadap pembentukkan karakter anak. karena untuk menjadi orang tua single parent tentu tidak mudah, sosok ibu single parent diharuskan memerankan peran ayah untuk anaknya, sosok ayah single parent pun harus memerankan perannya sebagai ibu sekaligus. Menjadi orang tua single parent mempunya beberapa hambatan dalam mendidik anak, dan dalam membentuk karakter anak, namun setiap orang tua mempunyai caranya sendiri dalam berkomunikasi dengan anak. pembentukkan karakter anak dapat di bentuk dari masa bayi hingga dewasa, maka dari itu pola berkomunikasi sangatlah penting dalam menciptakan keharmonisan hubungan 
Website: https://ojs.unikom.ac.id/index.php/common DOI Jurnal: https://doi.org/10.34010/common

DOI Artikel: https://doi.org/10.34010/common.v4i2.3284

antara orang tua single parent dan anak. Pola komunikasi antara orang tua single parent kepada anak sangatlah penting bagi pembentukkan karakter anak. karena bila hubungan orang tua dan anak baik maka anak akan memberikan respon positif dalam segala aspek. Namun bila hubungan antara orang tua dan anak kurang harmonis, cenderung akan menimbulkan respon yang negatif dari anak. bagaimana cara orang tua single parent berkomunikasi dengan anaknya untuk membentuk karakter anak. berikut kerangka penelitian dapat dilihat pada gambar 1 di bawah ini:

Gambar 1 Kerangka Pemikiran

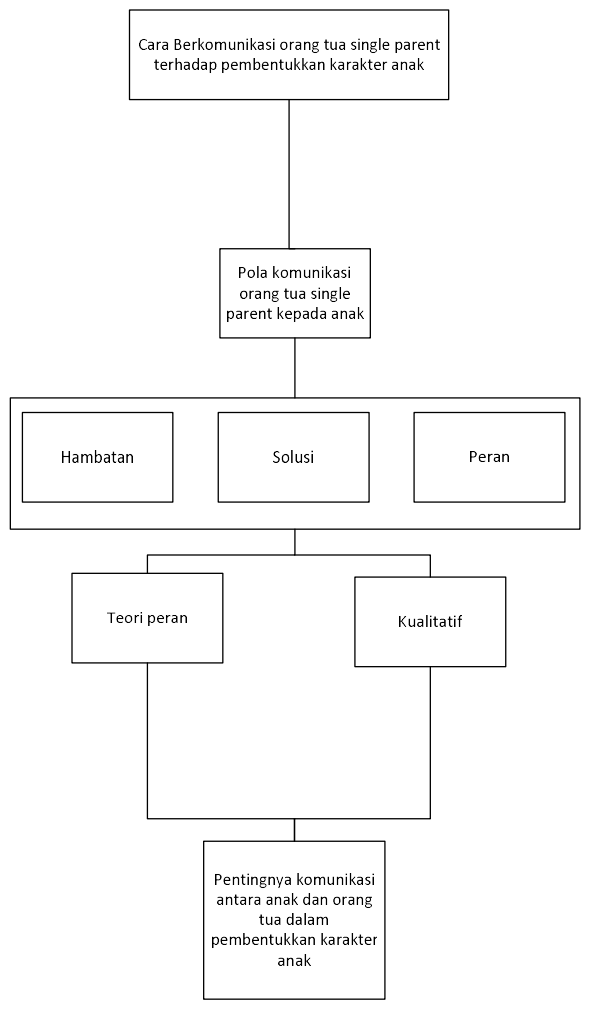

(Sugiyono, 2016)

\section{Objek dan Metode Penelitian}

\subsection{Metode Penelitian}

Metode penelitian yang digunakan oleh peneliti adalah metode penelitian kualitatif, karena peneliti ingin memahami tentang fenomena yang dialami oleh subjek penelitian. Subjek yang ada di penelitian ini adalah pola komunikasi orang tua single parent terhadap pembentukkan karakter anak. Peneliti ingin memahami bagaimana peran orang tua single parent memerankan peran ayah dan ibu.

Penelitian kualitatif lebih meneliti melalui riset yang bersifat deskriptif dan cenderung menggunakan analisis data. Proses dan makna (perspektif subjek) lebih ditonjolkan dalam penelitian kualitatif. Landasan teori juga dapat dijadikan patokan agar penelitian bisa fokus dengan data yang ada dilapangan. Dengan menggunakan landasan teori juga memberikan gambaran tentang bagaimana penelitian kita. Dalam peneltian kualitatif ini peneliti bisa memanfaatkan data yang ada, dan juga bisa menggunakan teori yang ada sebagai bahan untuk menjelaskan penelitian tersebut, dan berakhir dengan suatu teori yang bersangkutan dengan penelitian.(Sugiyono, 2016)

Dalam penelitian ini peneliti menggunakan metode fenomenologi sebagai landasan penulisan dan pembahasan. Penelitian ini mempelajari tentang manusia mengambil tindakan dan keinginan yang dicapai. Dalam hal ini mempelajari tujuan dari pola komunikasi orang tua single parent dalam membentuk karakter anak. fenomenologi menggunakan pengalaman langsung yang dialami oleh manusia. Manusia akan mengetahui apasaja pengalaman yang sudah didapat dari peristiwa yang sudah dialami oleh manusia tersebut. Dalam hal ini bertujuan untuk mempelajari bagaimana orang tua single parent berkomunikasi dengan anaknya dalam pembentukkan karakter.

Fenomenologi dapat dijadikan sebagai landasan utama untuk memahami realitas. Apa 
yang dapat diketahui oleh seseorang adalah apa yang dialami dengan orang yang bersangkutan. Stanley Deetz mengemukakan tiga prinsip dasar fenomenologi:

1. Pengalaman dapat mempengaruhi pengetahuan seseorang. Karena yang bersangkutan harus melalui pengalam tersebut agar bisa belajar.

2. Makna yang terdiri dari potensi hidup seseorang. Bagaimana cara seseorang memandang sesuatu dari sudut pandang orang tersebut.

3. Bahasa merupakan hal yang penting dalam berkomunikasi untuk mendapatkan pengalaman, karena melalui bahasa kita dapat mendefinisikan dan menjelaskan sesuatu dalam pikiran kita.

Proses interpretasi itu merupakan hal yang penting dan sangat utama dalam studi fenomenologi. Interprestasi adalah proses yang aktif dalam pemberian makna dari suatu pengalaman, interprestasi merupakan realitas bagi seorang individu. Pemikiran fenomenologi berdasarkan peristiwa atau situasi yang dialami oleh diri sendiri agar mendapatkan makna itu sendiri. Kondisi ini akan berlangsung terusmenerus, setiap pengalaman baru akan selalu mendapatkan makna yang baru.(Morissan, 2018).

\subsection{Objek dan Subjek Penelitian}

Objek dalam penelitian ini adalah pola komunikasi orang tua single parent dalam membentuk karakter anak, penelitian ini lebih kedalam cara berkomunikasi orang tua single parent kepada anak.

Subjek dalam penelitian ini adalah orang tua single parent yang akan di wawancarai untuk menjadi bahan penelitian ini. Adapun penelitian ini dibagi menjadi 5 narasumber, 2 ayah single parent, $3 \mathrm{ibu}$ single parent. Narasumber tersebut antara lain:

1. Ibu Dra. Marifa Ayu Kencana, MIS. Umur 52 tahun, pekerjaan PNS, mempunyai 2 anak, alasan menjadi orang tua single parent karena bercerai.

2. Ibu Niken. Umur 45, pekerjaan ibu rumah tangga, mempunyai 4 anak, alasan menjadi orang tua single parent karena meninggal dunia.

3. Ibu Novi. Umur 50 Tahun, pekerjaan pedagang, mempunyai 4 anak, alasan menjadi orang tua single parent karena meninggal dunia.

4. Ayah Very. Umur 35 tahun, pekerjaan pemandu wisata, mempunyai 2 anak, alasan menjadi orang tua single parent karena bercerai.

5. Ayah Wakur. Umur 52 tahun, pekerjaan wiraswasta, mempunyai 2 anak, alasan menjadi sngle parent karena meninggal dunia.

\section{Hasil dan Pembahasan}

\subsection{Pola komunikasi orang tua single parent terhadap anak}

Komunikasi antara orang tua single parent dengan anak pun sangat berpengaruh dalam pembentukkan karakter setiap anak. Berikut adalah hasil dari penelitian peneliti, karena tidak semua orang tua single parent dapat berkomunikasi dengan baik kepada anak, karena beberapa faktor yang menyebabkan komunikasi antara orang tua dengan anak tidak baik, namun ada juga yang sangat mengutamakan komunikasi dengan anak. hasil dari penelitian ini pola komunikasi orang tua terbagi jadi 3 yaitu:

1. Pola Komunikasi membebaskan (Permissive)

Di mana pola komunikasi ini, orang tua lebih membebaskan pilihan anak. pola komunikasi permissive orang tua lebih cenderung mengalah dan mengikuti segala kemauan anak dengan secara berlebihan. Cara orang tua single paren dalam membiarkan Anaknya kebebasan dalam mengambil suatu 
keputusan. sehingga anak akan merasa tidak diperdulikan lagi oleh orang tuanya. Bahkan ketika anak melakukan suatu kesalahan pun orang tua tidak akan terlalu menanggapi dengan tegas dan serius, orang tua cenderung lebih mengalah dan memaklumi sikap anak. Sehingga anak tidak bisa mengetahui di mana letak kesalahan yang telah ia perbuat, dan anak tidak akan tahu halhal apa saja yang semestinya tidak harus di ulangi lagi dikemudian hari.

2. Pola Komunikasi Otoriter (Authoritarian)

Cara berkomunikasi
menggunakan pola komunikasi otoriter orang tua cenderung kaku ketika sedang berkomunikasi dengan anak. orang tua lebih keras dalam mendidik anak. Dalam pola komunikasi ini, orang tua berpendapat bahwa anak memang harus mengikuti kemauan orang tua dan mengikuti apa yang orang tua inginkan, tidak diberikan kebebasan dalam berpendapat dan juga memilih pilihan. Karena apapun peraturan yang ditetapkan oleh orang tua, semata-mata untuk kebaikan anak. Namun tanpa disadari oleh orang tua bahwa pola komunikasi ini dapat membawa akibat yang buruk bagi perkembangan karakter anak dan cara berpikir anak di kemudian hari. Orang tua tidak mau repot berpikir bahwa peraturan yang kaku seperti itu justru akan menimbulkan serangkaian efek. Orang tua hanya berpikir bahwa apa yang dia lakukan demi kebaikan anak, namun salah besar sikap orang tua yang keras dalam berkomunikasi dengan anak menimbulkan perkembangan yang buruk.

3. Pola Komunikasi Demokratis (Authoritative)

Pola komunikasi orang tua yang demokratis lebih terbuka antara orang tua dan anak, anak di bebaskan untuk memilih pilihannya sendiri. Orang tua yang menerapkan pola komunikasi demokratis akan lebih mementingkan kepentingan anak tetapi tidak ragu untuk mengendalikan mereka. Orang tua juga akan mendorong anak-anaknya untuk bersikap mandiri. Meski orang tua akan tetap menetapkan batasan yang jelas terhadap anaknya, agar anak masih dalam pengawasan dan pengendalian dia, walaupun anak di bebaskan untuk memilih apa yang mereka inginkan, orang tua tetap akan mengawasinya. Komunikasi demokratis ini terjadi secara dua arah, di mana sikap orang tua yang lebih mencerminkan sisi kehangatan dan penuh kasih sayang kepada anaknya.

Dalam hasil penelitian ini rata-rata menerapkan pola komunikasi demokratis, namun ada juga yang permissive. Ibu niken cenderung menerapkan pola komunikasi permissive kepada anak-anaknya.

"Cara ibu berkomunikasi ke anak itu bedabeda, berhubung anak yang paling gede itu ga terlalu deket sama ibu jadi ya begitu tanya atau ngobrolpun seperlunya, kalau ke anak kedua ibu mah biasa saja mungkin karena cewe kali yah jadi ga begitu susah. Kalau sama anak yang ke tiga ibu mah kan ya susah dia kan punya keterbatasan mental, kalau anak ibu yang terakhir kan masih kecil jadi ya berkomunikasi sewajarnya saja."

Ketika orang tua terlalu membebaskan anak, dan anak akan diberikan nilai baik dan buruknya kepada anak, ketika anak mengambil keputusan tersebut. Kebiasaan anak cenderung lebih tidak terarah. Komunikasi yang kurang antara orang tua dan anak dapat menyebabkan adanya tidak terbukaan antara anak dan orang tua.

Pola komunikasi ibu Marifa lebih kepada anak menerapkan pola komunikasi demokratis, di mana ibu membebaskan anaknya untuk 
Website: https://ojs.unikom.ac.id/index.php/common

DOI Jurnal: https://doi.org/10.34010/common

DOI Artikel: https://doi.org/10.34010/common.v4i2.3284

memilih pilihan mereka. Tapi masih dalam pantauan ibunya.

"Mamah ikutin saja pola komunikasi yang sesuai sama anak. semakin remaja ya ikutin pola anak remaja seperti apa, karena mamah juga kan pernah remaja jadi tahu harus gimana, jadi lebih diarahkan saja. Karena pola asuh orang tua mamah ke mamah itu moderat, lebih terbuka membebaskan anak-anaknya berkembang." Karena dengan diterapkannya pola komunikasi demokratis dapat menimbulkan suasana keluarga yang lebih hangat, harmonis dan penuh kasih sayang. Karena hampir semua orang tua menerapkan pola komunikasi demokratis di mana anak dibebaskan untuk memilih pilihan mereka, namun selalu diingatka oleh orang tua konsekuensi yang dia dapat jiga memilih pilihan itu.

\subsection{Hambatan dan solusi dalam memperbaiki komunikasi antara orang tua single parent dengan anak}

Komunikasi adalah salah satu jembatan untuk menyampaikan pesan antara komunikator dan komunikan, menjadi orang tua single parent tentu mempunyai banyak hambatan yang dialami, tapi setiap orang tua mempunyai caranya masing-masing ketika ada hambatan dengan anak. Hambatan yang dirasakan oleh ayah Wakur ketika mempunyai hambatan dengan anaknya, "kadang suka salah persepsi antara yang bapa maksud dan yang anak tangkep, tapi ya bapa ngatasinnya dengan cara ngasih tahu pelan-pelan ke anak. tapi alhamdulillahnya merka cuman marah sebentar terus ya baik lagi begitu, ngerti sama kondisi orang tua."

Hambatan dalam berkomunikasi pasti selalu dialami, namun dibalik semua hambatan akan selalu ada solusi untuk menyelesaikannya. Berbeda dengan ayah Very, hambatan yang dirasakan mengenai jarak dengan anak keduannya karena beda pulau.
"Salah satu hambatan terbesar komunikasi terbesar itu ketersediaan waktu dan jarak, apalagi sama anak yang ke dua mah jauh jaraknya juga di Lombok, tapi ya kalo sama anak yang pertama mah kan ada disini di Bandung. Ya paling hambatannya karena miss komunikasi antara om sama anak, tapi da di kasih pengertian dikit juga ngerti sih. Solusi yang diberikan yaa sering berkomunikasi sama anak yang jauh mah, kalau yang di sini mah di kasih pengertian saja."

Beberapa faktor penghambat komunikasi antara orang tua single parent dengan anak:

1. Kurangnya komunikasi dengan anak, dapat membuat anak merasa tidak dipedulikan oleh orang tuanya.

2. Kesalah pahaman yang sering dialami antara orang tua dan anak.

3. Adanya jarak dan waktu yang yang membuat orang tua jarang berkomunikasi dengan anak.

Solusi yang diberikan ketika orang tua single parent kepada anak:

1. Sering berkomunikasi walaupun hanya lewat telepon

2. Memberikan penjelasan/pengertian kepada anak agar anak tidak salah paham

3. Selalu meluangkan waktu untuk anak.

Memahami kondisi orang tua single parent yang tidak mudah dalam mendidik anak karena yang biasanya ada yang membantu dalam memikirkan anak, ketika menjadi single parent harus memikirkan semuanya sendiri. hambatan yang dirasakan oleh single parent ketika berkomunikasi dengan anak misalnya, ayah menginginkan anak tidak pulang larut malam. Namun anak tidak menerima omongan ayah karena anak berasumsi bahwa omongan ayah hanya ingin mengekang kebabasan dirinya. Setelah dijelaskan oleh ayah maksud tidak di izinkan pulang larut malam karena bahaya bagi anak perempuan, anak baru memahaminya. 
Website: https://ojs.unikom.ac.id/index.php/common

DOI Jurnal: https://doi.org/10.34010/common

DOI Artikel: https://doi.org/10.34010/common.v4i2.3284

\subsection{Orang tua single parent memerankan sosok ayah/ibu untuk anak}

Memerankan dua peran sekaligus tentu tidak mudah bagi orang tua single parent, ketika ibu single parent harus berperan menjadi ayah bagi anak, dan ayah single parent pun harus berperan menjadi ibu ketika mereka di tinggalkan oleh pasangannya masing-masing, penyebab menjadi single parent bisa disebabkan oleh perceraian/ ditinggal meninggal dunia. Cara ibu Novi memerankan peran ibu sekaligus ayah untuk anak-anaknya dengan cara tergas kepada anak-anak menggunakan pola komunikasi demokratis, "Mamah selalu berusaha menjadi sosok ibu sekaligus ayah yang baik buat anak-anak, mamah juga suka tegas ke anak-anak karena kalo mamah ga tegas nanti mereka ga akan mandiri, karena mamah ingin anak-anak mamah itu pada mandiri, kuat"

Selain mencari nafkah orang tua single parent pun harus memikirkan bagaimana anak mendapatkan peran ayah/ibu dengan baik, karena tidak mudah memerankan dua peran sekaligus. Peran-peran yang dilakukan oleh orang tua single parent kepada anak selain memrankan sosok ayah/ibu, tetapi menjadi orang tua single parent pun harus bisa membagi waktu antara pekerjaan dengan anak, mendidik dan membimbing anak, menjadi sahabat untuk anak, dan memberikan nasihat kepada anak. karena guru pertama bagi anak adalah orang tua (keluarga).

\section{Kesimpulan dan Rekomendasi}

Berdasarkan dari hasil pembahasan dan penelitian, maka diperoleh beberapa kesimpulan terhadap penelitian peneliti "pola komunikasi orang tua single parent terhadap pembentukkan karakter anak" maka peneliti dapat memberikan kesimpulannya sebagai berikut:

Pola komunikasi orang tua yang berbeda-beda dapat membentuk karakter anak dengan cara yang berbeda. Jika anak didik oleh pola komunikasi Permissive, Authoritative,
Authoritaria, orang tua akan mendapatkan respon yang berbeda dari setiap anak. Jika orang tua menerapkan pola komunikasi authoritative anak akan lebih terarah dalam pembentukkan karakternya dan hubungan mereka jauh lebih harmonis. Tetapi bila orang tua menanamkan pola komunikasi yang permissive anak cenderung tidak terarah, karena orang tua kurang tegas dalam menidik dia, justru pola komunikasi ini membuat anak semakin jauh. Pola komunikasi yang tepat untuk orang tua single parent adalah pola komunikasi authoritative, di mana komunikasi antara orang tua single parent dan anak sangat baik, di mana orang tua selalu berkomunikasi dengan anak.

Hambatan dan solusi orang tua single parent dalam berkomunikasi dengan anak dapat terjadi dengan kurangnya interaksi antara orang tua dan anak, sehingga banyak terjadi miskomunikasi antara orang tua dan anak. Hambatan yang di alami oleh orang tua single parent Kurangnya komunikasi dengan anak, Jarak dan waktu yang membuat mereka jauh, kurangnya keterbukaan antara orang tua kepada anak menjadi kesalah pahaman dalam menyampaikan pesan. Solisi yang dilakukan dengan saling berkomunikasi dan keterbukaan satu sama lain, meluangkan waktu untuk anak agar anak merasa dianggap ada oleh orang tua.

Rekomendasi kepada orang tua single parent yang memerankan sosok ayah/ibu bagi anakanaknya walaupun tidak mudah untuk mnjadi orang tua single parent. Dalam penelitian ini orang tua single parent selalu berusaha menjadi sosok ayah/ibu yang baik untuk anaknya. Berusaha mengerti kebutuhan anak, dan orang tua single parent pun menyesuaikan peran jika anak membutuhkan sosok ayah/ibu, orang tua single parent harus bisa menjadi tempat cerita anak jika anak sedang merasa sedih/senang, orang tua single parent harus bisa membagi waktu antara kerjaan dan anak. 


\section{Daftar Pustaka}

Bandung, K. A. K. 2019. Sistem Informasi Penelusuran Perkara Pengadilan Agama Bandung. http://sipp.pabandung.go.id/list_perkara/page/17/ZjhO RGdXc1JIUU5kbGp3OEVzTGcyTDVT SkpCQ05UQ0tZN1FyN3gwWmN5OGR2 Q1NZVWRJajBUWm9BVytRUnhzUGV oa0Ivdy9SM0dSaFVTWFdxd055MEE9P $\mathrm{Q}==/$ MTlxaVdlME5US1FIbTdWcFJsS1J hWUFweERONDBVaDRscUI1Y21zS3F yQ01YMHkyc3lqK1IwaGhmQ1Avd1lk

Morissan. 2018. Teori Individu Hingga Massa (Riefmanto (ed.); 4th ed.). Prenada Media Group.

Sarwono, S. W. 2010. Teori-Teori Psikologi Sosial. In PT. Rajagrafindo Persada.

Sudjana, N. 2002. Dasar-dasar proses mengajar. In Bandung: Sinar Baru Algensindo.

Sugiyono. 2016. Memahami Penelitian Kualitatif. Bandung: Alfabeta.

Supriyono, Iskandar, H., \& Sucahyono. 2015. Pendidikan Keluarga Dalam Perspektif Masa Kini. 1-124.

Wiryanto. 2004. Pengantar Ilmu Komunkasi. Jakarta: Grasindo. 